\title{
CONTRIBUIÇÕES DO MESTRADO PROFISSIONAL EM EDUCAÇÃO PARA A FORMAÇÃO DOCENTE
}

\author{
Neusa Banhara Ambrosetti ${ }^{1}$ \\ Ana Maria Gimenes Corrêa Calil ${ }^{2}$
}

\section{Resumo}

Este artigo discute os resultados de uma pesquisa que buscou conhecer a perspectiva de participantes de um Mestrado Profissional em Educação sobre as contribuições do curso para o seu desenvolvimento profissional, e as possíveis repercussões dessa experiência para a atuação profissional desses mestres e mestrandos. O estudo fundamenta-se em autores que vêm discutindo as relações entre pesquisa acadêmica e pesquisa da prática, e o papel da formação no desenvolvimento profissional docente. Na abordagem metodológica recorreu-se ao envio de um questionário on-line, encaminhado a alunos concluintes de um MPE. Os dados indicam que os estudos teóricos articulados à análise das práticas e à apropriação de procedimentos da pesquisa científica constituem um novo olhar sobre a realidade, os alunos, o contexto de trabalho e a profissão docente, tornando o mestrado uma experiência transformadora das concepções e práticas desses profissionais.

Palavras chave: Mestrado Profissional em Educação; Formação Docente; Desenvolvimento profissional

\footnotetext{
${ }^{1}$ Doutora em Psicologia da Educação pela PUC-SP. Possui Pós-doutorado junto ao Programa de Estudos Pósgraduados em Educação: Psicologia da educação, da PUC-SP. É professora do Mestrado Profissional em Educação da Universidade de Taubaté. Endereço: Pró-reitoria de Pesquisa e Pós-graduação da UNITAU, Rua Visconde do Rio Branco, 210, CEP 12020-040, Taubaté, SP, Brasil. Endereço eletrônico: nbambrosetti@uol.com.br

${ }^{2}$ Doutora em Psicologia da Educação pela PUC-SP. É professora do Mestrado Profissional em Educação e do curso de Pedagogia, da Universidade de Taubaté. Endereço: Pró-reitoria de Pesquisa e Pós-graduação da UNITAU, Rua Visconde do Rio Branco, 210, CEP 12020-040, Taubaté, SP, Brasil. Endereço eletrônico: ana.calil@unitau.com.br
} 


\section{INTRODUÇÃO}

A constituição dos mestrados profissionais em educação (MPE) é recente no Brasil, e sua implantação tem sido permeada por dúvidas e questionamentos quanto à relevância dessa modalidade de formação. Segundo relatório da comissão que analisou as condições e perspectivas dos mestrados profissionais em educação (ANPED-FORPRED, 2013), o primeiro mestrado profissional na área foi criado em 2009, na Universidade Federal de Juiz de Fora. A partir daí ocorre um rápido aumento no número de cursos, registrando-se 42 MPEs em funcionamento no país em 2016 (BRASIL, 2016), o que mostra a dimensão dessa expansão.

A ampliação dos MPEs vem impulsionando as discussões em torno da finalidade e identidade dessa modalidade de curso, no campo dos debates sobre as relações entre a universidade e o mundo do trabalho e sobre o papel da pós-graduação stricto sensu, frente às transformações sociais e tecnológicas em curso na sociedade contemporânea. Como já observava Gatti, em análise ainda pertinente nos dias atuais (GATTI, 2001), prevalece nos círculos acadêmicos uma concepção dos mestrados e doutorados como nível de ensino voltados para a formação de pesquisadores, e mesmo sua função na formação de docentes para o ensino superior tem sido minimizada.

É interessante observar que a perspectiva de mestrados e doutorados voltados para a formação profissional estava presente na origem desses cursos no Brasil. No parecer CFE 977/65, que vai estabelecer as bases da pós-graduação no país, encontram-se as ideias de mestrado e doutorado "em pesquisa" e "profissional". Os legisladores esclarecem que a pósgraduação sensu stricto deveria ser entendida como “[...] uma superestrutura destinada à pesquisa, cuja meta seria o desenvolvimento da ciência e da cultura em geral, o treinamento de pesquisadores, tecnólogos e profissionais de alto nível’(ALMEIDA JUNIOR. et al., 2005, p. 165).

Como observa Gatti (2001), gestado no contexto do regime militar, o documento inserese numa política indutora da formação de "capital humano", que via na produção científica e tecnológica um fator essencial para o desenvolvimento do país. Embora tenha produzido alguns avanços, essa política acaba levando à concentração de conhecimento em poucos grupos, em algumas regiões do país, conferindo à pós-graduação stricto sensu uma conotação elitista e excludente:

Revista Reflexão e Ação, Santa Cruz do Sul, v. 24, n. 3, p.85-104, Set./Dez. 2016.

http://online.unisc.br/seer/index.php/reflex/index 
CONTRIBUIÇÕES DO MESTRADO PROFISSIONAL EM EDUCAÇÃO PARA A FORMAÇÃO DOCENTE

A integração da pesquisa como parte da vida universitária, como processo induzido, via mestrados e doutorados, acaba por criar uma vinculação excessiva entre a pesquisa e a pós-graduação na maioria das instituições, quando o desejável seria um espalhamento das atividades de investigação científica dentro de toda a vida acadêmica. (GATTI, 2001, p. 109).

Apesar das profundas mudanças no país, a ideia de pós-graduação stricto sensu voltada para o desenvolvimento profissional continua enfrentando resistência na academia, passando o mestrado profisssional a ser entendido como uma titulação menor, restrita à formação prática e não condizente com a formação do pesquisador. Como observa Ribeiro (2005), essas resistências às relações com o setor produtivo ocorrem em parte pela identificação da formação profissional com os interesses empresariais, colocando a universidade a serviço do capital. Diversos questionamentos quanto à validade dos mestrados profissionais levaram a Fundação de Coordenação de Aperfeiçoamento de Pessoal de Nível Superior (CAPES), em sucessivas manifestações, a reafirmar o entendimento de que os mestrados profissional e acadêmico não diferem em termos de titulação e possibilidades de atuação na docência universitária, bem como de continuidade dos estudos no doutorado (BARROS, 2008).

Em seminário promovido pela CAPES em 2005, intitulado "Para além da academia: a pós-graduação contribuindo para a sociedade", o órgão governamental estimula a discussão sobre os mestrados profissionais, reafirmando o entendimento quanto à necessidade da contribuição do conhecimento acadêmico para o desenvolvimento econômico e social do país. Discutindo as questões que emergiram no encontro, Ribeiro (2005) ressalta que é necessário refletir sobre as relações entre a academia e o mundo do trabalho, e aponta o risco de que, especialmente as áreas de Ciências Humanas e Sociais, “[...] fechem-se no mundo universitário e não transfiram, para aqueles que de fato agem no mundo da prática, os meios mais novos e aptos a lutar contra a miséria e a iniquidade".

Nesse mesmo sentido, Gatti (2001) destaca que é preciso repensar a vocação dos programas de mestrado e doutorado, agregando a suas finalidades a formação de quadros profissionais com maior nível de sofisticação em relação ao oferecido nas graduações, para atendimento às demandas dos setores sociais:

[...] parece que será necessária a construção de um novo tipo de compreensão quanto ao papel dos mestrados e doutorados, entendendo que conhecimento aprofundado pode conviver com problemas de trabalho mais ou menos imediatos, e que as diferenças entre modalidades formativas podem situar-se quanto à perspectiva temática e não necessariamente em uma desqualificação no nível formativo. (GATTI, 2001, p. 112). 
AMBROSETTI, N. B.; CALIL, A. M. G. C.

Essas considerações são especialmente pertinentes quando discutimos o papel do mestrado profissional em educação. Concordando com a essencialidade da pesquisa e produção de conhecimento como função inerente à universidade, sendo a pós-graduação stricto sensu o locus por excelência dessa tarefa, caberia questionar: até que ponto o conhecimento na área, produzido pelas pesquisas realizadas nos mestrados e doutorados, tem trazido contribuições para as práticas educativas?

Evidentemente, não cabe estabelecer relação direta entre a produção acadêmica e a melhoria da qualidade da educação brasileira, mas entendemos que é válido esperar que a pósgraduação stricto sensu, como observa Ribeiro (2006), tenha uma dimensão formadora capaz de promover um salto qualitativo na formação e na atuação profissional do aluno.

Enquanto docentes em um curso de Mestrado Profissional em Educação recentemente implantado, essas considerações nos levam a alguns questionamentos: as pesquisas e conhecimentos desenvolvidos no curso trazem efetivamente contribuições ao campo da prática, traduzindo-se em melhores condições de formação, ensino e aprendizagem para os sujeitos abrangidos pela atuação desses mestres e mestrandos? A participação no mestrado profissional em educação vem tornando esses alunos melhores profissionais e afetando positivamente suas práticas em seus contextos de trabalho?

A partir desses questionamentos, este artigo discute os resultados de uma pesquisa que buscou conhecer a perspectiva de participantes de um Mestrado Profissional em Educação sobre as contribuições do curso para o seu desenvolvimento profissional, e as possíveis repercussões dessa experiência para a atuação profissional desses mestres e mestrandos.

\section{A PESQUISA NA FORMAÇÃO E DESENVOLVIMENTO PROFISSIONAL DOS EDUCADORES.}

Se há consenso quanto à importância da pesquisa como componente essencial aos mestrados - sejam eles acadêmicos ou profissionais - uma discussão que se coloca quando pensamos no mestrado profissional em educação é sobre a forma de pesquisa mais adequada para essa modalidade de curso.

Como lembra Gatti (2010), a construção metodológica da investigação em educação deve considerar as características e questões relevantes do campo de conhecimento. A autora ressalta que a educação, como outras áreas envolvidas com a atuação social, é área do agir, e essa característica de intervenção na realidade social demanda formas de conhecimento específicas: 
CONTRIBUIÇÕES DO MESTRADO PROFISSIONAL EM EDUCAÇÃO PARA A FORMAÇÃO DOCENTE

A compreensão deste agir intencional, destas formas de intervenção no real que é de caráter profissional, requer um outro tipo de conhecimento, aquele conhecimento que diz respeito à relação/incorporação de teorias com/em práticas intencionais, com finalidades socialmente definidas. A reflexão, o estudo, a investigação sobre seus modos de intervir é que constitui sua área privilegiada de construção de conhecimento. Aí encontramos suas especificidades. Nem por isso seus estudos perdem o caráter científico, ao contrário, é neste recorte que sua contribuição é insubstituível. (GATTI, 2010, p. 5, grifo da autora).

Conforme esse entendimento, a pesquisa nos mestrados profissionais da área deve observar essa dupla dimensão da educação, área de conhecimento e área de atuação profissional, tratando assim da produção de conhecimento comprometido com o agir intencional, que implica compreensão fundamentada e refletida das práticas, com vistas às possibilidades de sua transformação.

Uma autora que traz contribuições relevantes para esclarecer a concepção de pesquisa no mestrado profissional em educação é André (2016, p. 30), ao discutir o lugar da pesquisa na formação do "profissional da prática pedagógica", a partir da experiência no Mestrado Profissional em Educação: Formação de Formadores, da PUC de São Paulo.

No esclarecimento dessa questão, a autora retoma discussões a respeito da pesquisa acadêmica e da pesquisa aplicada, recorrendo principalmente à conceituação apresentada por Gatti, em apresentação no I Fórum de Mestrados Profissionais em Educação. Na concepção de Gatti (2014, apud ANDRÉ, 2016. P. 34), enquanto a pesquisa acadêmica “[...] tem a teoria como ponto de partida e de chegada e a problematização é construída com base na teoria ou em referentes teóricos", a pesquisa engajada (expressão usada pela autora) “[...] tem a realidade empírica como ponto de partida e de chegada e visa evidenciar fatos específicos, pela compreensão de situações localizadas, buscando soluções e propondo alternativas". André (2016) observa que, apesar de terem objetos diferentes, as duas modalidades de pesquisa aproximam-se na exigência de rigor e cuidado metodológico, inerente a toda pesquisa.

Segundo a autora, a pesquisa no mestrado profissional deve formar o pesquisador prático, entendido como sujeito autônomo, capaz de fazer uma leitura crítica e compreensiva da realidade, no sentido de sua transformação. Para tanto,

É preciso que desenvolva uma atitude de pesquisador, o que vai exigir a aquisição de habilidades, tais como, formular questões acerca da realidade que o cerca, buscar dados e referências para elucidar as questões que o intrigam, saber tratar os dados e referências localizados e ser capaz de expressar seus achados. Isso vai implicar o aprendizado da problematização, da argumentação, da revisão bibliográfica, da produção e análise de dados, assim como a sistematização e relato dos achados. (ANDRÉ, 2016, p. 33- 34). 
AMBROSETTI, N. B.; CALIL, A. M. G. C.

O desenvolvimento dessa atitude investigadora, essencial ao pesquisador da prática, é destacado também nos estudos de Cochran-Smith e Lytle (1999), quando analisam as relações entre investigação, conhecimento e prática profissional. Ao discutirem o conceito de conhecimento-da-prática, concebido como o conhecimento produzido nas relações entre a investigação intencional das práticas e as teorias já produzidas, como fonte de questionamento e interpretação dessas práticas, as autoras observam que esse entendimento transcende a distinção entre conhecimento formal e conhecimento prático, permitindo uma compreensão ampliada e transformada da prática. Avançando nessa perspectiva, propõem a ideia de investigação como postura, processo que pode trazer resultados promissores à formação e ao desenvolvimento profissional dos professores.

Ao abrir possibilidades para o exercício da pesquisa pelo professor, favorecendo o desenvolvimento dessa postura investigadora, o mestrado profissional pode tornar-se espaço privilegiado no desenvolvimento profissional docente. Como lembra Ludke (2001, p. 51), processos formativos fundados na prática de pesquisa asseguram o exercício da docência de forma mais crítica e autônoma, constituindo, “[...] um recurso de desenvolvimento profissional, na acepção mais ampla que esse termo possa ter”.

Segundo Marcelo (2009), o conceito de desenvolvimento profissional é adequado à compreensão do professor como profissional do ensino, abrangendo as noções de formação permanente, formação em serviço, formação contínua, entre outras. Dentre as características apontadas por Marcelo (2009), com base em estudos de diversos autores, destacam-se alguns aspectos que nos ajudam a refletir sobre o mestrado profissional enquanto espaço de desenvolvimento profissional dos educadores: o desenvolvimento profissional é entendido como um processo contínuo, ao longo da vida, capaz de abarcar a formação inicial e a formação em exercício nos diversos períodos da carreira profissional; compreende processos formativos que têm relação com as situações concretas de trabalho dos professores; entende os professores como sujeitos ativos e reflexivos, portadores de conhecimentos que devem ser considerados como base para a construção de novos conhecimentos e práticas; pode ser um processo individual, mas processos colaborativos são especialmente favoráveis ao desenvolvimento profissional; assume diferentes formas e ocorre em diversos contextos, mas é sempre voltado para a transformação das práticas, dos próprios sujeitos e dos contextos de trabalho. Caracteriza-se, assim, como “[...] um aprendizado não linear, mas evolutivo, cujo resultado não se percebe apenas na mudança das práticas de ensino, mas também no 
CONTRIBUIÇÕES DO MESTRADO PROFISSIONAL EM EDUCAÇÃO PARA A FORMAÇÃO DOCENTE

pensamento sobre o como e porquê dessa prática" (MARCELO e VAILLANT, 2009, p. 77, tradução das autoras).

Na perspectiva de Day (2001, p. 20-21):

O desenvolvimento profissional envolve todas as experiências espontâneas de aprendizagem e as atividades conscientes planificadas, realizadas para benefício, directo ou indirecto, do indivíduo, do grupo ou da escola e que contribuem, através destes, para a qualidade da educação na sala de aula. É o processo através do qual professores, enquanto agentes de mudança, reveem, renovam e ampliam, individual e coletivamente, o seu compromisso com os propósitos morais do ensino, adquirem e desenvolvem, de forma crítica, juntamente com as crianças, jovens e colegas, o conhecimento, as destrezas e a inteligência emocional, essenciais para uma reflexão, planificação e prática profissionais eficazes, em cada uma das fases das suas vidas profissionais.

Abrangente e complexa, a definição do autor revela todos os prismas passíveis de provocar mudanças nas concepções e comportamentos do professor, sejam elas de natureza cognitiva, relacional ou emocional. Tem implícito, ainda, o reconhecimento do professor como agente do próprio desenvolvimento.

Imbernón (2010) acrescenta que o professor não pode limitar-se a refletir somente sobre a sua prática docente; é preciso que essa reflexão ultrapasse as paredes da instituição com o propósito de analisar, de maneira mais ampla, os objetivos e interesses implícitos na educação, o que inclui a compreensão da realidade social. Para que isso ocorra, a formação docente deve renovar-se numa proposta que vá além das questões da atuação em sala de aula, considerando o meio, o grupo, a instituição, a comunidade, as bases implícitas, as decisões e atitudes dos professores. Tem-se, assim, que ressaltar no conceito de desenvolvimento profissional a dimensão coletiva, o que implica promover o trabalho colaborativo relacionado às instituições educativas e às comunidades de prática.

O mestrado profissional seria, então, um espaço de desenvolvimento profissional dos mestrandos, conferindo uma nova dimensão à trajetória de formação já percorrida por eles, desenvolvendo um olhar mais crítico e fundamentado sobre a realidade educacional, estimulando capacidades criativas e reflexivas, provocando-os a produzirem conhecimentos profissionais que reflitam nas suas práticas.

\section{CONTEXTO E PROCEDIMENTOS METODOLÓGICOS DO ESTUDO}

O curso foco do presente estudo é desenvolvido por uma universidade regional, situada no estado de São Paulo, com larga tradição na formação de professores e estreita relação com os sistemas públicos de ensino da região, tanto pelo oferecimento de cursos de especialização 
AMBROSETTI, N. B.; CALIL, A. M. G. C.

lato sensu, como pelos programas de formação continuada de professores, desenvolvidos em parceria com essas redes. A proposta para o Mestrado Profissional em Educação insere-se nesse contexto, fundada no conhecimento da realidade educacional e orientada para uma formação profissional de sólida base teórica, comprometida com as questões da educação pública regional.

Segundo essa proposta, o curso estrutura-se em torno da temática formação de professores e práticas de ensino para a educação básica, a qual, na proposta, desdobra-se em dois eixos de pesquisa: inclusão e diversidade sociocultural, que discute políticas e práticas de educação inclusiva e diversidade sociocultural nos contextos escolares, e formação docente e desenvolvimento profissional, que tem por objeto de estudo os processos de formação docente para a educação básica, na perspectiva do desenvolvimento profissional.

O curso em questão é o primeiro MPE na região, e teve início em 2014. A oferta de novas turmas é anual, com cerca de 20 vagas a cada ano. Considerando a realidade do corpo discente, composto em sua maioria por profissionais da educação básica atuantes nos sistemas públicos de ensino, as aulas ocorrem no período noturno, duas vezes por semana, além de atividades programadas mensais, no período vespertino. O curso é pago, e parte dos estudantes beneficiam-se de bolsas fornecidas pelas instituições em que trabalham.

Têm-se atualmente três turmas em andamento. Os alunos da primeira turma já defenderam suas dissertações, enquanto os da segunda turma concluíram os créditos e dão continuidade às dissertações. $\mathrm{O}$ estudo proposto tem como sujeitos esses alunos, mestres ou mestrandos das duas primeiras turmas do MPE.

Tendo em vista os objetivos do estudo, buscou-se, na abordagem metodológica, uma aproximação com a perspectiva desses sujeitos, procurando recuperar a memória de sua experiência durante o curso e sua percepção quanto à repercussão do processo formativo na sua atuação profissional.

Para tanto, foi elaborado um questionário com 20 questões fechadas, compreendendo uma caracterização socioeconômica dos mestrandos, sua trajetória de formação, experiência profissional anterior e atuação profissional atual, entre outros aspectos, no sentido de construir um perfil desses alunos. Foram incluídas também três questões abertas, convidando o participante a descrever sua experiência no curso, as possíveis contribuições dessa experiência para o seu desenvolvimento profissional e as repercussões dessa participação na sua atuação profissional. Os questionários foram enviados por meio do aplicativo Google Docs, e dos 36 questionários enviados foram obtidas 25 respostas, o que perfaz quase $70 \%$ do total de 
CONTRIBUIÇÕES DO MESTRADO PROFISSIONAL EM EDUCAÇÃO PARA A FORMAÇÃO DOCENTE

participantes. Para preservar o sigilo dos dados, especialmente considerando que as pesquisadoras integram o corpo docente do curso, os respondentes não foram identificados, assim são referidos na análise pelos números de ordem das respostas no questionário.

As respostas foram submetidas a sucessivas leituras, interrogando-se os dados a partir das questões colocadas no estudo e buscando, progressivamente, penetrar os seus significados. Nos resultados apresentados a seguir delineia-se inicialmente um perfil dos participantes, construído com base nas questões fechadas, como forma de contextualizar e compreender os aspectos que emergem no exame das respostas às questões abertas.

\section{A EXPERIÊNCIA DO MPE NA PERSPECTIVA DOS ALUNOS}

\subsection{Quem são os alunos do MPE}

Analisando os dados do questionário, observa-se que a maioria dos participantes (55\%) tem entre 29 e 39 anos, e $45 \%$ têm 40 anos ou mais. Neste segmento há 5 mestrandos com mais de 50 anos, o que sugere que a inexistência de mestrados anteriormente na região dificultou o acesso desses participantes à pos-graduação stricto sensu. Corrobora esta hipótese o fato de que todos eles cursaram pós-graduação lato sensu, sendo que $56 \%$ deles fizeram dois cursos de especialização e quase a metade dos respondentes cursou mais de uma graduação, o que indica o interesse do grupo pela continuidade na formação.

Os participantes são majoritariamente casados (72\%), mulheres (80\%) com filhos (60\%). A renda familiar de 64\% deles varia de 4 a 10 salários mínimos, o que, segundo critérios do IBGE, situa-os na classe C. Apenas 36\% recebem bolsa parcial de suas instituições para cursar o mestrado, o que indica que os custos devem pesar no orçamento familiar.

O grupo tem longa experiência na carreira docente. Apenas 4 participantes têm menos de 10 anos de experiência; 40\% têm entre 10 e 19 anos de experiência; 36\% têm entre 20 e 29 anos e 2 têm mais de 30 anos de atividade docente. Essa experiência refere-se principalmente à atividade na educação básica, mas vários deles revelaram expectativa de que a titulação no MPE possibilite o acesso ao magistério superior. A maioria (84\%) trabalha em instituição pública, municipal ou estadual. A carga horária semanal de trabalho dos mestrandos é alta: apenas 3 trabalham menos de 20 horas semanais; 28\% deles têm carga horária de 25 a 36 
AMBROSETTI, N. B.; CALIL, A. M. G. C.

horas; e, 60\% cumprem uma carga horária de 40 horas ou mais, o que dá a dimensão das dificuldades que enfrentam para cumprir as exigências do curso.

Em síntese, temos um grupo com idade média em torno de 40 anos, composto majoritariamente por profissionais que atuam em redes públicas de educação básica, em atividades de ensino ou relacionadas à gestão, coordenação e orientação, o que inclui a formação de professores. Dois participantes atuam na docência no ensino superior e um exerce assessoria como psicólogo escolar. Os participantes envidam grandes esforços para cursar o mestrado, devido ao investimento de tempo e aos recursos necessários. Têm uma longa trajetória profissional e experiências diversificadas, que trazem para as discussões nas aulas do mestrado. Buscam no curso, além de evolução na carreira, referências para sua atuação profissional, aprofundamento dos conhecimentos e fundamentação para suas práticas.

\title{
4.2 ingresso no universo da pesquisa: uma experiência transformadora
}

Ao relatarem suas primeiras impressões sobre o curso, os mestrandos manifestam uma dupla perspectiva: as dificuldades enfrentadas inicialmente, ao se depararem com as leituras e demandas do MPE, para as quais muitos deles não se sentem preparados, mas também o encantamento com a cultura acadêmica e a inserção na pesquisa, que desvelam aspectos da realidade até então vistos por eles na perspectiva do senso comum.

As respostas evidenciam o esforço dos alunos (profissionais em atividade com intensa carga de trabalho) para cumprirem as exigências do curso, que demanda tempo, esforço e dedicação, e também a percepção do crescimento vivenciado nesse processo. Os registros mostram esses sentimentos contraditórios:

\begin{abstract}
A experiência com o mestrado é uma relação de amor e ódio. De crescimento e sacrifícios. Uma relação sadomasoquista, devido às atribulações pessoais e profissionais do dia a dia, o que às vezes gera uma angústia. Gostaria de ter mais tempo disponível para poder me dedicar mais. Apesar de tudo considero uma experiência de crescimento profissional e pessoal, que transforma o seu olhar, suas atitudes, desperta reflexões acerca da sua profissão e que Ihe proporciona novas atitudes e amplia horizontes. (P. 7).
\end{abstract}

A fala acima resume bem a perspectiva de vários participantes, apontando as dificuldades que por vezes os levam à quase desistência, ao mesmo tempo em que valorizam 
CONTRIBUIÇÕES DO MESTRADO PROFISSIONAL EM EDUCAÇÃO PARA A FORMAÇÃO DOCENTE

o rigor e o nível de aprofundamento do curso e reconhecem que vivenciam uma experiência transformadora, no aspecto pessoal e também no aspecto profissional.

A transformação torna-se possível na medida em que os estudos teóricos, articulados às análises das práticas, constituem um novo olhar sobre a realidade educacional mais ampla e sobre o próprio contexto de trabalho, como se observa neste extrato:

Existe um grau, um salto profissional e pessoal, anterior ao MPE até esta etapa do curso. As leituras proporcionam a visão por ângulos diferentes que vai além do processo educacional. Parece que é só desembaçar a vidraça para enxergar e compreender o que se passa no nicho onde divido o trabalho com outros profissionais, buscando novas estratégias para o ensino. (Part. 6).

Especialmente importante para essa experiência transformadora, segundo os alunos, é o ingresso no universo da pesquisa e da discussão acadêmica, território até então desconhecido para eles:

Esta experiência está sendo de suma importância para meu crescimento profissional, visto que tornar-se um produtor de conhecimento científico e ter a oportunidade de compartilhar conhecimento através da pesquisa traz à tona uma visão nunca alcançada por mim até então. (P. 17).

Os depoimentos mostram o ingresso no MPE como uma iniciação ou um rito de passagem (GENNEP, 1978, apud RIBEIRO, 2006), promovendo uma mudança qualitativa na formação dos sujeitos. Convergem, assim, para os aspectos que Ribeiro (2005, p. 314) aponta como características essenciais aos mestrados - sejam eles acadêmicos ou profissionais o rigor acadêmico e a promoção de uma mudança de qualidade no aluno: "Ele não sai igual ao modo como entrou. Ele não está sendo treinado ou informado. Está sendo formado".

Os relatos acima evidenciam o quanto a inserção na cultura acadêmica voltada para a pesquisa, e a interação em um grupo que traz para a sala de aula a diversidade de suas experiências, promovendo a reflexão fundamentada nas leituras dos textos teóricos e na discussão dessas práticas, pode ser fértil para o desenvolvimento profissional desses sujeitos. Revelam ainda a valorização, pelos participantes, de conhecimentos que permitem ampliar o olhar sobre a realidade escolar, e que não estavam presentes na trajetória de formação anterior ao mestrado:

O curso proporcionou para mim uma abertura no modo de ver a "Educação", o que era discutido e apresentado durante as aulas 
AMBROSETTI, N. B.; CALIL, A. M. G. C.

nunca tinha estudado durante a graduação e nem na formação continuada das redes que atuo. (P. 10)

As respostam suscitam a discussão sobre as possibilidades formativas no mestrado profissional, em relação à formação na graduação e pós-graduação lato sensu, já que os participantes declaram larga vivência nesses cursos. É recorrente nas respostas a referência à diversidade das experiências do mestrado e à diferença trazida pela pesquisa como fonte de um olhar mais apurado sobre a realidade:

Trouxe novos conhecimentos, despertou reflexões, nova posturas, incertezas, visão mais ampla e deu segurança para acompanhar 0 ritmo acelerado de tantas mudanças na sociedade, que respingam dentro dos muros da escola. O conhecimento de como fazer uma pesquisa e a importância e contribuição da mesma para sua prática e para o desenvolvimento e evolução da humanidade e educação. (P. 7).

Ao discutir o papel da pesquisa na formação profissional dos professores, André (2001, p. 59) destaca que "[...] fazer pesquisa significa possuir conhecimentos, baseados em coleta e análise de dados, de forma sistemática e rigorosa, o que requer do pesquisador um trabalho com um corpus teórico, vocabulário próprio, conceitos e hipóteses específicos”, e observa que, considerando as condições de trabalho dos professores, seria exigir muito que desenvolvessem pesquisas com esses requisitos de rigor.

As respostas dos participantes confirmam o quanto levar a cabo essa tarefa é difícil para eles, sem as condições adequadas para tanto, mas também como essa possibilidade é valorizada e percebida como essencial ao seu desenvolvimento:

Muito deste amadurecimento pessoal e profissional que 0 mestrado me trouxe veio da forma que fui orientada em minha pesquisa: aberta e dialógica. Tive liberdade para pesquisar a realidade com a qual trabalho há anos: desde a escolha do tema, sujeitos, da técnica utilizada, do referencial teórico. Esta oportunidade ampliou meu olhar sobre o tema estudado $e$ representou uma experiência muito importante na minha vida profissional, inclusive abrindo novos caminhos, novas frentes de atuação. (P.21).

O relato acima nos leva a concordar com Cochran-Smith (2006), quando ressalta que é necessário pensar em pesquisas êmicas, olhando "de dentro e por dentro" da profissão, ou seja, pensar e pesquisar a escola de dentro da escola, com profissionais que realmente conhecem e vivem o cotidiano escolar "na pele". Acreditamos que o mestrado profissional Revista Reflexão e Ação, Santa Cruz do Sul, v. 24, n. 3, p.85-104, Set./Dez. 2016.

http://online.unisc.br/seer/index.php/reflex/index 
CONTRIBUIÇÕES DO MESTRADO PROFISSIONAL EM EDUCAÇÃO PARA A FORMAÇÃO DOCENTE

possa tornar-se esse espaço onde a pesquisa acadêmica, sem prescindir do rigor científico na produção de conhecimento, venha se articular com a pesquisa da prática, trazendo a investigação para dentro da formação dos professores e concretizando a ideia de professor pesquisador, tão presente nas discussões acadêmicas quanto distante das nossas práticas formativas.

\subsection{Formação, desenvolvimento profissional e prática educativa}

A busca pelo Mestrado Profissional, por parte de professores, coordenadores e gestores, revela o seu interesse pelo desenvolvimento profissional. Conforme apresentado anteriormente, são profissionais que fizeram inúmeros cursos ao longo da carreira, têm intensa carga de trabalho, e se dispõem a grandes esforços na busca pela formação.

Ao discutirem as repercussões do MPE em sua atuação profissional, os participantes destacam diversos aspectos positivos, que têm em comum a valorização da base teórica como elemento fundamental para compreensão e transformação das práticas, como se observa neste extrato:

O MPE contribui, constantemente, no processo de aprendizagem e reflexão, afetando diretamente as minhas práticas em sala de aula. O processo observacional e a compreensão do cotidiano escolar que antes pertencia ao senso comum escolar cede espaço para as relações com os autores estudados, apropriando-me de novas ideias e novas formas na condução e resolução dos casos no processo de ensino, bem como na organização geral da escola. (P. 6).

A manifestação do aluno traz à tona uma questão fundamental na formação de professores: o papel da teoria na formação e na prática docente, remetendo às discussões de Roldão (2007) sobre a natureza do conhecimento profissional docente. Segundo a autora, o saber envolvido na ação docente torna-se saber profissional quando os saberes teóricos e da experiência se integram na ação pedagógica, transformando-se em "[...] agir informado, que é o acto de ensinar enquanto construção de um processo de aprendizagem de outros e por outros - e, nesse sentido, arte e técnica, mas fundada em ciência” (ROLDÃO, 2007, p. 101).

Ao que parece, esse processo em que experiência e teoria se realimentam, traduzindo-se no agir fundamentado e produzindo práticas mais compreensivas e interpretativas que os Revista Reflexão e Ação, Santa Cruz do Sul, v. 24, n. 3, p.85-104, Set./Dez. 2016. 
AMBROSETTI, N. B.; CALIL, A. M. G. C.

profissionais expressam em suas respostas, vincula-se ao desenvolvimento da atitude de pesquisador (André, 2016) favorecida no aprendizado da pesquisa.

Um aspecto interessante, destacado em vários depoimentos, é que as mudanças não se limitam às ações individuais, mas se estendem aos contextos de trabalho dos mestrandos, especialmente no caso daqueles que exercem funções de formação:

Durante as formações dos docentes, a forma de gerir processos, recursos e pessoas. $O$ desejo de ampliar o conhecimento dos docentes, de dar base teórica e de qualidade para que tenham 0 conhecimento necessário para uma reflexão da prática que possa ser transformadora. O quanto a minha participação no mestrado foi contagiante para que outros professores se sentissem motivados para se inscreverem no curso de mestrado. Hoje na minha escola temos cinco profissionais cursando mestrado. (P. 7).

Bem, além de rever toda minha atuação como docente e me reciclar, percebo que posso colocar meus conhecimentos adquiridos no Mestrado em ação no sentido de modificar a realidade dos contextos escolares em que atuo, pois são comunidades extremamente carentes, na periferia, onde vejo a necessidade de transformações profundas, e me sinto capaz de propor reflexões junto a elas, oriundas dos conhecimentos obtidos aqui. (P. 9).

Ao discutir formação de professores, Imbernón (2010, p. 49) observa que ela acontece num processo de integração, e não de isolamento, destacando que um dos eixos na formação permanente é o desenvolvimento profissional da instituição educativa, o que implica promover "[...] a passagem da experiência de inovação (isolada e individual) à inovação institucional". Os relatos acima nos permitem perceber que os efeitos da formação não se restringem ao participante, mas se espraiam em seus contextos de atuação, potencializando as repercussões do desenvolvimento individual e ampliando seus resultados.

Um aspecto significativo, que emerge em diversos relatos, refere-se à percepção da valorização profissional dos mestrandos, pelo reconhecimento de seus pares e pela abertura de novas possibilidades profissionais:

Primeiro, os colegas apresentam um comportamento que se aproxima da admiração pelo fato da participação num curso stricto sensu. O mestrado possibilita também, um avanço de base salarial considerável, promovendo uma sensação de retorno financeiro significativo. Por último, o retorno aos estudos e ao mestrado especificamente, me fez retomar a necessidade de 
CONTRIBUIÇÕES DO MESTRADO PROFISSIONAL EM EDUCAÇÃO PARA A FORMAÇÃO DOCENTE

publicar as minhas ações como educador; hoje, além de escrever sobre a minha temática de pesquisa, me esforço para tornar público e reconhecido pelos pares todas as ações que desenvolvo como coordenador de extensão. (P. 23).

Esse curso contribuiu muito para a minha prática profissional, houve no decorrer desse tempo um amadurecimento essencial em minha vida. Eu consegui me ver como professor, reconheci a minha profissão, pois antes eu possuía muitos questionamentos e desânimos sobre o "ser professor. (P. 10).

Os registros acima nos levam a refletir sobre uma questão posta por Marcelo (2009): a estreita relação entre desenvolvimento e identidade profissional. $O$ autor ressalta que o desenvolvimento profissional, entendido como um processo que vai se construindo à medida que os educadores ganham mais conhecimento, experiência e consciência profissional, reflete também na constituição da identidade, ou seja, na forma como o profissional vê a si mesmo e é visto pelos outros. Essa evolução:

[...] integra o compromisso pessoal, a disponibilidade para aprender a ensinar, as crenças, os valores, o conhecimento sobre as matérias que ensinam e como as ensinam, as experiências passadas, assim como a própria vulnerabilidade profissional (LASKY, 2005, apud MARCELO, 2009, p. 11).

Os registros evidenciam esse processo de mudança pessoal e profissional que afeta e transforma também as práticas dos participantes. Nos depoimentos, eles detalham vários aspectos dessa transformação:

Posso dizer que duas são as questões em que fui mais influenciado pelo mestrado. As relações com os estudantes, no sentido da afetividade. E as práticas "inovadoras", pelo menos às minhas praticas: desenvolvimento de aula, avaliação, planejamento das metas, autoavaliação, etc. (P. 8).

A participação no mestrado repercutiu em minha prática, por exemplo, no que diz respeito à observação de forma mais sistemática de como o conhecimento é transmitido e captado pelos alunos e como acontece esse processo de ensino e aprendizagem. Também nas reflexões acerca das individualidades que permeiam 0 fazer pedagógico, a influência da história de vida dos alunos na sua aprendizagem e na importância de refletir constantemente sobre minha atuação profissional (P. 14). 
AMBrosetTI, N. B.; CALIL, A. M. G. C.

Os extratos acima indicam um aspecto que permeia muitas respostas. Ao descreverem as transformações na sua atuação profissional, os mestrandos destacam uma capacidade citada por Roldão (2008) como essencial ao desempenho profissional: compreender os propósitos de suas ações, pensar sobre elas e avaliar seus resultados. Na perspectiva dos participantes do MPE, os conhecimentos e experiências desenvolvidos no curso fundamentam suas ações, permitindo avaliar com maior clareza suas práticas cotidianas e compreender seu papel de professores:

As reflexões propostas nas aulas e pelas professoras estão presentes em meu cotidiano, modificando muito de minha prática. Muitas questões que me incomodavam foram sendo explicitadas, tornando-se mais claras. Passei a compreender muito de minha prática e de meus colegas. [...] Ser professor é ser um profissional que sabe o que faz, como faz, porque faz e para quem faz. Tem clareza de suas ações e das consequências das mesmas. (P. 16).

Em suas respostas, os alunos dão pistas sobre os processos formativos que promovem esse desenvolvimento, como destaca a participante 20, ao refletir sobre os ganhos em sua atuação como formadora de professores:

Nas formaçôes com os professores apliquei algumas dinâmicas de grupo desenvolvidas no curso; realizei leituras de autores importantes na área da formação docente, enriquecendo-me com a troca de saberes; desenvolvi a dissertação, compreendendo, na prática, todas as etapas de uma pesquisa; dediquei-me à escrita acadêmica, por meio do exercício constante durante a pesquisa, na busca de uma autoria, tendo por base teórica a leitura e o diálogo entre autores; participei de encontros, seminários e palestras que tiveram impacto positivo em meu cotidiano, enquanto profissional atuante na rede pública de ensino. (P. 20).

Este relato, que sintetiza uma perspectiva presente na maioria dos registros, leva-nos de volta à reflexão sobre o papel da pesquisa na formação docente, conforme observação de André (2016), ao evidenciar quanto o desenvolvimento profissional dos mestrandos é favorecido pela apropriação de procedimentos inerentes à pesquisa científica, como o registro, a escuta e o olhar atentos, a apropriação crítica dos textos teóricos, a publicação e partilha do conhecimento produzido.

Os depoimentos dos participantes reafirmam a relação fertilizadora entre pesquisa e prática e o papel essencial do MPE enquanto espaço de produção de saberes inerentes à profissão, e, por isso, capazes de revelar, questionar e transformar as práticas educativas.

Revista Reflexão e Ação, Santa Cruz do Sul, v. 24, n. 3, p.85-104, Set./Dez. 2016.

http://online.unisc.br/seer/index.php/reflex/index 


\section{ALGUMAS CONCLUSÕES}

Os resultados do estudo sugerem que o MPE pode desempenhar papel relevante na formação dos profissionais da educação, respondendo ao desafio apontado por Gatti (2001, p. 114) à pós-graduação stricto sensu, de "[...] ampliar suas perspectivas sociais, sem perder a ciência como referencial", atendendo às demandas de produção de conhecimento socialmente relevante e democratização do acesso aos contingentes de profissionais instados a dividir seu tempo entre trabalho e estudo.

Os dados revelam profissionais que enfrentam dificuldades para cumprir as exigências do curso, mas permanecem nele, engajados no esforço pela continuidade na formação, impulsionados pela curiosidade, pela descoberta do prazer da investigação e pela busca de conhecimento para atender aos questionamentos da prática. São profissionais que assumem protagonismo pelo próprio desenvolvimento profissional, mas entendem esse processo como construção a ser compartilhada com seus pares, em seus espaços de trabalho. Trazem para discussão e reflexão coletiva nas aulas do mestrado seus conhecimentos e experiências, constituindo uma pequena comunidade de aprendizagem, reunindo professores e alunos em torno do projeto formativo comum.

$\mathrm{Na}$ perspectiva dos participantes, o curso constitui um momento privilegiado num processo contínuo de desenvolvimento profissional, contribuindo para um olhar mais informado sobre a realidade, o aluno, o contexto de trabalho e a própria profissão docente, que se traduz em práticas mais fundamentadas e reflexivas.

Entendemos que este seria o papel do mestrado profissional em educação: introduzir a pesquisa no campo da prática, produzir conhecimento profissional dentro da profissão e formar profissionais capazes de agir de maneira transformadora em seus contextos de atuação, desenvolvendo práticas favoráveis à educação das crianças e jovens das escolas brasileiras.

Concluindo, concordamos com Roldão (2008, p. 48), quando afirma que é "na formação destes profissionais de ensino [...] que poderá jogar-se - julgamos - a melhoria da qualidade da educação, mediada pela sólida qualidade profissional destes seus actores”.

\section{CONTRIBUTIONS OF PROFESSIONAL MASTERS IN EDUCATION TEACHER}

\section{FORMATION}




\begin{abstract}
This article discusses the results of a research that aimed to know the prospect of participating in a Professional Masters in Education about the course contributions to their professional development, the possible repercussions of this experience in professional practice. The study is based on authors who have been discussing the relationship between academic research and practical research, and the role of formation in teacher professional development. In the methodological approach it was an online questionnaire forwarded to senior students of Professional Masters in Education. The data indicate that the theoretical studies articulated the analysis of practices and appropriation procedures of scientific research constitute a new look at the reality, the students, the working environment and the teaching profession, making the Masters course a transformative experience of the concepts and practices of professionals.
\end{abstract}

Keywords: Professional Masters in Education; Teacher Formation; Professional Development

CONTRIBUCIONES DE LA MAESTRÍA PROFESIONAL EN EDUCACIÓN PARA LA FORMACIÓN DEL DOCENTE

\title{
Resumen
}

Este artículo discute resultados de una encuesta que buscó conocer la perspectiva de participantes de un Mestrado Profesional en Educación sobre las contribuciones del curso para su desarrollo profesional y las posibles repercusiones de esa experiencia en la actuación profesional. Este estudio se basa en autores que han discutido las relaciones entre investigación académica e investigación de la práctica y el rol de la formación en el desarrollo del profesional docente. En el abordaje metodológico se recurrió al envío de un cuestionario en línea para estudiantes concluyentes de un MPE. Los datos indican que los estudios teóricos relacionados al análisis de las prácticas y el dominio de procedimientos de investigación científica constituyen un nuevo abordaje de la realidad, de los estudiantes, del contexto de 
CONTRIBUIÇÕES DO MESTRADO PROFISSIONAL EM EDUCAÇÃO PARA A FORMAÇÃO DOCENTE

trabajo y de la profesión docente, lo que hace de la maestría una experiencia transformadora de las concepciones y prácticas de esos profesionales.

Palabras clave: Maestría Profesional en Educación. Formación del docente. Desarrollo profesional.

\section{REFERÊNCIAS}

ALMEIDA JUNIOR, Antonio et al. Parecer CFE no 977/65, aprovado em 3 dez. 1965. Revista Brasileira de Educação, Rio de Janeiro: ANPED; Campinas: Autores Associados, n.30, p. 162-173, set./dez. 2005.

ANDRÉ, M. E. D. A. Pesquisa, formação e prática docente. In: ANDRÉ. M. (org.). O papel da pesquisa na formação e na prática dos professores. Campinas, SP: Papirus, 2001.

ANPED-FORPRED. Relatório das condições e perspectivas dos Mestrados

Profissionais na área de educação. Goiânia, set. 2013. Disponível em:

<www.anped.org.br/sites/default/files/relatorio_comissao_forpred_2013.pdf >

Acesso em: 04 Mai de 2016.

BARROS, Lucivaldo V. Notas sobre o Mestrado Profissionalizante: a experiência do Centro de Desenvolvimento Sustentável da UnB. Revista Brasileira de Pós-graduação, Brasília: Capes, vol. 5, n. 10, p. 353-364, dez. 2008. Disponível em:

<http://ojs.rbpg.capes.gov.br/index.php/rbpg/article/viewFile/158/152>. Acesso em: $30 \mathrm{Abr}$ de2016.

BRASIL. MEC. Fundação Capes. Cursos recomendados/reconhecidos. 2016. Disponível em: <https://sucupira.capes.gov.br/sucupira/public/consultas/coleta/programa/quantitativos/quantit ativoAreaAvaliacao.jsf>. Acesso em: 04 Mai de 2016.

COCHRAN-SMITH, Marylin. Taking Stock in 2006: evidence, evidence everywhere. Journal of Teacher Education, v. 57, n 1, p. 6-12, jan./feb. 2006. http://doi/10.1177/0022487105283347

COCHRAN-SMITH, Marylin; LYTLLE, Suzan L. Relationships of knowledge and Practice: teacher learning in communities. Review of Research in Education, n. 24, p. 249-305, jan.1999. http://doi/10.3102/0091732X024001249

DAY, Cristopher. Desenvolvimento profissional de professores: os desafios da aprendizagem permanente. Porto: Porto Editora, 2001.

GATTI, Bernardete A. Reflexão sobre os desafios da pós-graduação: novas perspectivas sociais, conhecimento e poder. Revista Brasileira de Educação, Rio de Janeiro: ANPED; Campinas: Autores Associados, n. 18, p. 108-116, set-dez. 2001. 
Algumas considerações sobre procedimentos metodológicos nas pesquisas educacionais. Revista Educação em Foco, Juiz de Fora: UFJF, 2010. Disponível em: < http://www.ufjf.br/revistaedufoco/files/2010/02/07.pdf>. Acesso em: 02 Mai de 2016.

IMBERNÓN, Francisco. Formação continuada de professores. Porto Alegre: Artmed, 2010.

LUDKE, Menga. A complexa relação entre o ensino e a pesquisa. In: ANDRÉ. M. (Org.). $O$ papel da pesquisa na formação e na prática dos professores. Campinas, SP: Papirus, 2001.

MARCELO, Carlos. Desenvolvimento Profissional Docente: passado e futuro. Sísifo. Revista das Ciências da Educação, n. 08, p. 7-22, jan/abr. 2009.

Disponível em: <http://sisifo.fpce.ul.pt>. Acesso em: 30 Abr de 2016.

MARCELO, Carlos; VAILLANT, Denise. Desarollo Profesional Docente ¿Cómo se aprende a enseñar? Madrid: Narcea, 2009.

RIBEIRO, Renato J. O mestrado profissional na política atual da Capes. $R B P G$, vol. 2, n. 4, p. 8-15, jul. 2005. http://dx.doi.org/10.21713/2358-2332.2005.v2.72

Ainda sobre o mestrado profissional. $R B P G$, Brasília, v. 3, n. 6, p. 313-315, dez. 2006. Seção Debates. Disponível em:

<http://ojs.rbpg.capes.gov.br/index.php/rbpg/article/download/113/107>. Acesso em: 03 Mai de 2016.

ROLDÃO, Maria do Céu. Função docente: natureza e construção do conhecimento profissional. Revista Brasileira de Educação, Rio de Janeiro: ANPED; Campinas: Autores Associados, vol.12, n. 34, p. 94-103, jan./abr. 2007.

Formação de professores baseada na investigação e na prática reflexiva. In:

Conferência desenvolvimento profissional de professores para a qualidade e para a equidade da aprendizagem ao longo da vida. Lisboa: Ministério da Educação, 2008.

Data de recebimento: 06/05/2016

Data de aceite: 11/11/2016 